\title{
Dividend Policy and The Role of Capital Structure and Corporate Governance: A Case Study of Cement Factory in Pakistan
}

\author{
Muhammad Askar *
}

\begin{abstract}
This work investigates the impact of capital structure (CS) and corporate governance (CG) on dividend policy. The sample selected for this study includes all firms in the cement sector of the Pakistan stock exchange. The CS and CG are measured using the debt to equity ratio (DER) and managerial and institutional ownership mechanisms. The dividend policy $(D P)$ is measure using the dividend payout ratio. The fixed effect model of regression is used for estimation and correlation matrix. The data normality, autocorrelation and multicollinearity are also used as a tool of analysis. The results show no outliers problem in the data set and have the pair of variables firmly. We also demonstrate that CS and CG has a significant impact on dividend policy. It is concluded that CS and managerial ownership positively impacted dividend policy, while there is an insignificant impact on institutional ownership.
\end{abstract}

Keywords: Debt Ratio; debt to equity ratio; institutional ownership; managerial ownership; dividend policy; dividend payout ratio; fixed-effect model

\section{Introduction}

Various perspectives provide a distinct definition of the term corporate governance (CG). Nonetheless, it is the method by which commodities are administered and organized." As described by Fooladi and Nikzad Chaleshtori (2011) information, the term "Corporate Governance (CG)" is helpless to reciprocal and concepts that are limited. The procurement and estimation of capital are necessary for any financial management. It is also essential for any firm to estimate the capital requirement. This will help them to invest appropriately and can properly evaluate the investment. In this regard, the financial manager must define the role of capital structure (CS), corporate governance (CG) and dividend policy (DP), respectively.

In addition, it is also necessary to raise the wealth of shareholders. Consequently, it raises the importance of the respective firm due to an increase in shareholders' wealth. The long-term benefits are also significant to finance any company. The long-term benefits can secure the companies in diverse ways, such as sharing equities and preferences as well as a debenture. In short, we can say that the CS consists of debentures and shares. The sharing of equities and preferences mean that we own funds while the debenture is the borrowed or funding of debts. Therefore, the CS can be considered conjunction of equities, debts, and financing for a short duration. The CS depicted the finances of any firm by its entire actions and development and by utilizing the diverse funds (Shah

\footnotetext{
${ }^{*}$ Institute of Management Studies, University of Peshawar. Email: askarjaanstd@uop.edu.pk
} 
\& Khan, 2007). As we know, the money can be garnered from various assets, such as equities and debts, to run the business. For example, the equity can be organized as socks or retained earnings (RE), while debt is releasing contracts or long-term banknotes is one way to do this.

The DP also play an essential role in financial management (Sudana, 2011). It is the distributed profit among the owners in the business after tax payable. However, the RE is the profit, following deducting the tax, which can be utilized again in our businesses and not distributed among investors. Hence, we have two kinds of profits after-tax deduction, i.e., profit distributed among owners and profit re-invested into the business. As a result, the dividend is vital to understand as it is an essential task for any financial corporation.

There is a further vital factor of the dividend choice on a payment strategy. It is as to whether the cash is transferred back to the investors or re-invested by the company. Hence, the concept/dividend amount is different for different firms due to different DPs. After payable tax, the ratio of the distributed net profit is usually considered as dividend payout ratio (DPR). If the dividend is well completed, the company's values can increase due to a rise in the stock market. Alternatively, in case the dividend is not or less paid, the shared prices of the firm must also be low. Subsequently, the profit achieved by the firms is closely related to the dividend payment. For example, in case the company attained a significant income, paying dividends must be greater. Investors are considered the real proprietors of a limited obligation for companies (Brahmaiah, Srinivasan, \& Sangeetha, 2018). Shareholders/investors can get the shares because they are required to attain the rewards on investment. Furthermore, shareholders can be elected as directors. Afterwards, the directors are accountable to hire the managers and other staff to run the company. The employees are thought to be acting in favor of investors, but they must respect the company's policies bound them. Such strategies have the potential to increase profitability.

Effective organization governance processes seek to ensure that executives act on behalf of investors. It is a dominant participant in CG and financial management (Yasser, Entebang, \& Mansor, 2011). CG is a type of monitoring technique. It restricts as well as operates the business visibility to improve its profitability. Consequently, it seeks to increase value for shareholders (Monks \& Minow, 2004). It is also involved in investor perceptions of the benefits offered by the business's management team. The business's leader must be convinced, and they ought not to lighten or invest in companies that do not benefit from the profits earned by the shareholder. On the other hand, CG is linked with shareholders who have authority over executives (Shleifer \& Vishny, 1997).

Dewi, Suhadak, and Handayani (2017) used the least-square assessment to gather income reports from seven different banks per year, as depicted in Indonesia's stock exchange (IDX). It observes that both CS and CG were impacted on DP and the company's profit. It is also determined that CS has a crucial and positive impact on DP, whereas CG has no substantial adverse impact.

The finance industry has accounted for the majority of CS and CG research on DP. In the non-financial industry, unfortunately, the CS and CG on DP have not yet developed. As a result, this study investigates the impact of CS and CG on DP in the non-financial industry, employing Pakistan's cement industry as a research study. 
The financial executive must understand the significance of CS as well as CG concerning the company's DP. The economic leader will also make decisions based on the firm's CS as well as CG. CG has a large number of essential tools for efficient implementation. For example, when conversing on a huge panel, the senior managers' personnel may experience issues by default. Similarly, if external managers are self-sufficient and have the necessary expertise, they may be progressively used to make decisions and evaluate subordinates. In either way, CG plays an essential role in the company's performance.

\section{Literature Review}

Miller and Modigliani (1961) investigated the dividend unimportance concept in a perfect business's absence of taxation and financing expenses. The authors studied that dividend decision does not influence the firm's importance. As a result, it is an unsuitable resolution. The notion is that if dividend policy isn't taken into account, investor money will be impacted. Finally, Fama and Babiak (1968) put the Lintner revenue demonstration to the test. They maintained that the organizations would strive to increase revenues only when gains could be sustained later.

The authors Akhtar, Husnain, and Mukhtar (2012) investigated the variations of CS for the Pakistani textile industry. As an example, they selected thirty textiles firms. The company's exposures were adversely connected to the expense and TG development of prospects financing and the volume, scope, and value of the funding. Furthermore, due to its relatively diminutive size, those enterprises in Pakistan's spinning industry rely on internal finance rather than outward financing. Hijazi, Bin Tariq, et al. (2006) investigated the financial leverage of the cement industry in Pakistan. The goal was to investigate the cement company's distinct characteristics. The size and PF of the resources were also the explanatory factors. They utilized a technique known as OLS analysis. In the cement industry, they considered sixteen companies. Excluding the business scale, a hugely important outcome was discovered.

Shah and Khan (2007) looked into the factors influencing the CS of non-financial businesses listed on the Karachi stock exchange. The PF, company size, development, and TG factors were studied. They employed the technique of pooled regression. The results revealed that TG has a weak but favourable relationship with leverage. The scale was enormous, and this was a good thing to have. However, the development was slow and uneven. As a result, leverage had a detrimental and severe impact on growth. On the other hand, the PF was hostile, significant, and resilient with leverage, implying that the rational expectations assumption proved correct.

Asif and Aziz (2016) examined whether CS affects a company's worth or not. The examination was conducted on twenty cement companies listed on the Karachi Stock Exchange (KSE), Pakistan. The data was collected for ten years. Various factors were utilized in the assessment, such as return on the profit earned, common stock, and the total liabilities, to choose the independent variables by considering EVA as the predictor indicator. For analysis, inferential evaluation, linear regression, and OLS regression were used. As a result, they found that overall variables positively correlate and represent that 
CS is influencing the firm value.

Dewi et al. (2017) depicted the effects of CS as well as CG on DP and the company value at banks registered in the Indonesian Stock Exchange (ISE) using partial least square (PLS) analysis. The data were collected from the financial statements yearly. It has been found that CS has positively affected DP. CG has a negative non-significant effect on DP. CS has a significant positive impact on firms value. CG has a beneficial influence on the value of a company. The DP also has a pleasant non-significant influence on the importance of

firms. These outcomes will deliver an excellent decision to companies for any administration resolution.

Brahmaiah et al. (2018) illustrated the DP characteristics on the National Stock Exchange (NSE) recorded in India. From 2013 to 2018, the interactive panellist information methodology was applied to a group 135 of ninety-five NSE-listed companies. Income, availability, debt, volatility, company size, and in ationary were the primary predictors of India's dividend policy of chosen NSE listed companies. The findings show that income, availability, business size, and in ation had a substantial negative impact on the DP of the NSE sampled companies. The risk variable tends to have a negative and significant impact. Besides, the lagged dividend, investment opportunities, taxation, and yield curve does not significantly determine the DP.

\section{Theoretical Background}

\section{Capital Structure (CS)}

The first approach regarding CS was instructed by Durand (1952). He postulated that a modification in money leverage leads to a change in capital price. Suppose there is a rise in quantitative debt relation, CS increases and the weighted monetary value of capital decreases, resulting in an exceedingly higher firm's value. CS is the combination of each Share and debt (Shah \& Khan, 2007). Cash makes the business go which money comes from entirely different sources, namely, equity and debt. Debt comes within the bonds issue or long run notes owed, whereas equity is assessed as common shares, preferred shares or preserved earnings. CS variable evaluated by debt ratio (DR) and debt to equity ratio (DER). DR is measured to calculate the total liabilities by total assets, and the DER is measured by dividing total liabilities by total shareholders' equity. CS was assuming the DR and DER to know how much debt is required for a firm and how much equity is required. The firms need to take neither high percent debt nor take high percent equity.

\section{Corporate Governance (CG)}

The CG code was first given by SECP (Security Exchange Commission of Pakistan). It shows that CG has value-added to the corporate in rising in operation performance and avoiding frauds. The requirement for CG follows the need to scale back the conflicts of interest between stakeholders in firms. These clashes of interest seem as a consequence of branching needs between shareholders and higher management (Principal-Agent problem) and among shareholders (principal-principal problem). CG using managerial own- 
ership and institutional ownership mechanism inside and outside CG reduce the measurement error at the corporate level. Institutional ownership is the amount of a company's available stock owned by mutual funds, insurance companies, invested firms, private foundations. Institutional ownership is an external mechanism, While managerial ownership is the internal mechanism. Therefore, CG can be examined with how the owners think that the managers can benefit the firms. The investors are also confident that the manager must not darken or invest in a project that does not help linked with the support by the owners.

\section{Dividend Policy (DP)}

Van Horne and Wachowicz (2005) state that DP is a vital portion of corporate financing decisions. Thus, the foremost characteristic of the company's DP is to define the appropriate distribution of profits between dividend payments with the addition of retained earnings of the industry. The dividend is a profit after tax that is distributed to the owner of a business. Therefore, if a firm distributes the portion of the profit available after-tax to the owner, it is called the dividend. On the other hand, it means that some part of the profit is not given to the owner and will be retained in the business, and it will be called retained earnings. So when a firm has profit after tax, they have two choices, one is given to the owner in the form of a dividend, and the other is retained within the business in the name of retained earnings. The dividend is an essential task of the business's corporate financial policy. By announcing the dividend or not declaring the dividend, a firm is taking major corporate financial decisions. The manager will manage the whole system because the governors, who might designate managers, will elect the stockholders. Consequently, the managers control the entire organization to run the company. The managers are in charge of the stockholders' interests. They adhere to rules that maximize stakeholder profit.

\section{Conceptual Framework and Hypotheses}

This conceptual framework has illustrated the CS and CG that lead towards the DP. In the CS, independent variables are considered. The independent variables demonstrate the variation in the form of DR and DER variables. On the other side, the CG variable represents institutional ownership, and managerial ownership mechanisms are considered. Therefore, I have selected a proxy for DP that is the dividend payout ratio. The summary of the 200 overall conceptual framework is illustrated as in Fig. 1. In addition, there are two hypotheses.

$$
\begin{aligned}
& H_{o}: \text { The impact of CS on DP is negligible. } \\
& H_{1} \text { : The impact of CS on DP is considerable. } \\
& H_{o}: \text { The impact of CG on DP is negligible. }
\end{aligned}
$$


$\mathrm{H}_{2}$ : The influence of CG on DP is considerable.

\section{Methodology}

Depending on regression analysis from 2015 to 2019, the cement industries (included twenty-four enterprises) were selected as the research sample. The analysis used a descriptive scientific method to choose organizations to complete the workforce for analysis. The secondary data to determine the influence of CS, as well as CG upon DP, is also considered in this work. This work measured the variable of CS by DR and DER. CG is measured by managerial ownership and institutional ownership procedure, while DP is peroxide by DPR. For this study, CS data were acquired from the financial statements of yearly statements from cement industries. Furthermore, the CG data was collected through

financial statements. Eventually, the DP statistics were acquired from the trial balance of the cement sector's financial statements, which included 24 enterprises. These figures come from the financial statements of the cement industry, which comprised 24 companies. The association between the reliant and random variables was discovered during the inquiry. DP is the dependent variable, and CS and CG influence it. CS and CG are the independent variables. The expression is primarily convinced into our allocated parameters when we persuade the expression into our given variables, i.e.,

$$
D P R_{i t}=\beta_{0}+\beta_{1}\left(D R_{i t}\right)+\beta_{2}\left(D E R_{i t}\right)+\beta_{3}\left(I_{i t}\right)+\beta_{4}\left(M O_{i t}\right)+\epsilon
$$

where, $\mathrm{DR}=$ debt ration, $\mathrm{DER}=$ debt to equity ratio, $\mathrm{IO}=$ institutional ownership, $\mathrm{MO}$ $=$ Managerial ownership, and DPR $=$ Dividend payout ratio.

\section{Result and Discussion}

This part focuses on the report's results as well as subsequent debate in light of the objective and hypothesis. It includes step-by-step outcomes as well as repercussions that are explained. In the following region, these findings are represented.

\begin{tabular}{lccccc}
$\begin{array}{l}\text { Table 1 } \\
\text { Correlation Matrix }\end{array}$ & & & & \\
\hline \multicolumn{7}{c}{ DPR } & DR & DER & IO & MO \\
\hline DP R & 1 & & & & \\
DR & $-0.2942^{* *}$ & 1 & & & \\
DER & $0.7290^{* *}$ & $0.2522^{* *}$ & 1 & & \\
I O & -0.1486 & -0.0296 & $-0.0588^{* *}$ & 1 & \\
M O & 0.4413 & $-0.0709^{* *}$ & $-0.0449^{* *}$ & $-0.1983^{* *}$ & 1 \\
\hline
\end{tabular}

There is a substantial correlation of DPR with DR, DER, and MO in Table 1. The variables DER and MO had a favourable correlation, whereas DR had an adverse correlation. With the predictor variables, nevertheless, IO were shown to be unimportant. Between DR and DER \& MO, that is 0:25 and $-0: 07$, accordingly, there is a substantial favorable 
link, with the strength of linkage being larger with DER. With DR, IO are determined to be necessary.

In addition, the study mentioned above reveals a strong adverse link between DER, $\mathrm{IO}$, and MO. The level of unfavorable correlation between IO and MO is 19.83 percent.

\section{Panel Diagnostics (Selection of a Suitable Model)}

To choose an excellent basis for estimates, panel assessment testing is needed, as depicted in Table 2. Two tests show that the constant impact treatment is acceptable, and one is heading closer to Pooled OLS, so the Fixed Effect Model is adequate for the evaluation.

Table 2

Panel Diagnostics

\begin{tabular}{llcc}
\hline Tests & Models & P-Value & Decision \\
\hline Chow's Test & Pooled Regression vs. Fixed Effect Model & 0.0083 & Fixed Effect Model \\
Breusch Pagan & Pooled Regression vs. Random Effect Model & 0.84 & Pooled Regression Model \\
Hausman Test & Random Effect vs. Fixed Effect Model & 0.0328 & Fixed Effect Model \\
\hline
\end{tabular}

\section{Multicollinearity}

All the values of VIF shown in the table are less than 10, which reflect no problem of Multicollinearity in the model as shown in Table 3.

\begin{tabular}{|c|c|c|}
\hline Variable & VIF & Tolerance \\
\hline DR & 1.07 & 0.9321 \\
\hline DER & 1.07 & 0.9323 \\
\hline IO & 1.05 & 0.9533 \\
\hline $\mathrm{MO}$ & 1.05 & 0.9553 \\
\hline
\end{tabular}

\section{Durbin's Alternative Test for Autocorrelation}

The value of prob. Chi Square is 0:0643 which is more than 0:05 which reflects that there is no problem of autocorrelation in the model. The result is shown in Table 4.

\section{Data Normality}

The skewness and kurtosis values are between 1:96, and +1:96 are considered acceptable to show the normal univariate distribution. This is because it keeps the residual in a normally distributed manner. The outcomes are shown in Table 5. 
Table 5

Skewness and Kurtosis Table for Data Normality

\begin{tabular}{lccccc}
\hline Variable & Obs & Pr (Skewness) & Pr (Kurtosis) & adj chi2 (2) & Prob $>$ chi2 (2) \\
\hline DP R & 120 & 0.000 & 0.000 & 0.000 & 0.000 \\
DR & 120 & 0.000 & 0.027 & 24.84 & 0.000 \\
DER & 120 & 0.004 & 0.000 & 33.28 & 0.000 \\
I O & 120 & 0.000 & 0.001 & 40 & 0.000 \\
M O & 120 & 0.000 & 0.035 & 19.1 & 0.001 \\
\hline
\end{tabular}

\section{Regression (Fixed Effect model)}

In Table 6, R-square is 0.69 that indicates $69 \%$ entire variations in the dependent variable to vary the independent variables. F-Stats is 15:05, and its P-Value is 0:000. This demonstrates the importance of the whole explanatory variable. Individual independent variables such as DR, DER, and managerial ownership substantially impact the DPR. Corporate governance, on the other hand, is deemed negligible. The value of DR is 0:679, implying that a 1 unit increase in DR results in a 0:679 increase in the DPR.

Table 6
Regression (Fixed Effect model)
\begin{tabular}{lcccc} 
Variable & Coef. & Std. Err. & T & sig \\
\hline DR & 0.679 & 0.225 & 6.558 & 0.000 \\
DER & 0.554 & 0.177 & 9.667 & 0.000 \\
I O & -0.118 & 0.692 & 1.633 & 0.517 \\
M O & 0.387 & 0.147 & 5.522 & 0.001 \\
\hline
\end{tabular}

\section{Conclusion}

The study found an overall statistically significant effect of CS and CG on the cement sector's dividend policy in Pakistan. A superior DR results in a greater DP, and a better DER impacts dividend policy. Meanwhile, managerial ownership boosts a company's payout. This work is essential for administrative staff, practitioners and academia. The optimum CS can lead any industry towards better operational and financial performance, increasing the dividend payout, eventually. The greater dividend payout promotes the market for sustainable business procedures and will lead to the interest of the investors. Likewise, higher CG takes decisions towards the betterment of the organization. CS and CG can aid the organization significantly by providing excellent management techniques, policy implementation and review, efficient regulating, and suitable restrictions are all things that can help a business succeed. CG is an essential part of the developing world. It directly benefits the company by providing senior management instruction, abilities, supervision, and personal finance to increase legislation, auditing, and appraisal.

\section{Recommendation}

It is recommended that the business's management team tries to find stability between CS and DP. If a company wants to expand its value, it should focus on intuitive CS and 
maintain a strict grip over the Good CG technique. Furthermore, if assessing CS, the business's management team must avoid using excessive debt for investments. Using too much debt burdens businesses with interest payments, increasing the risk of bankruptcy. As long as the advantages are more significant, the additional debt is permissible. In contrast, the extra debt is not allowed if the sacrifice is made because the debt is higher. Eventually, if a corporation wants to expand its value, its management team should boost institutional and managerial possession.

\section{Limitation and Future Study}

The proposed research using the number of samples will be for the cement firms and other non-financial firms. The study anticipated offering the outcomes which will generalize the companies in Pakistan. The research duration will also be extended to a more significant sample and different varieties. The extension of the sample period will ultimately outperform the estimated relationship of each variable. This research used only CS and CG variables to determine their effect on the company's dividend policy. Future research is recommended to examine other financial variables that probably significantly impact dividend policy. It is also recommended to inspect the signs of good CG incomplete to get the best explanation and consequence for the investigation. 


\section{References}

Akhtar, P., Husnain, M., \& Mukhtar, M. A. (2012). The determinants of capital structure: A case from Pakistan textile sector (spinning units). In Proceedings of 2 nd International Conference on Business Management (Vol. 12, pp. 76-88).

Asif, A., \& Aziz, B. (2016). Impact of capital structure on firm value creation-evidence from the cement sector of Pakistan. International Journal of Research in Finance and Marketing, 6(6), 231-245.

Brahmaiah, B., Srinivasan, P., \& Sangeetha, R. (2018). Determinants of corporate dividend policy in India: a dynamic panel data analysis. Academy of Accounting and Financial Studies Journal, 22(2), 1-13.

Dewi, R. P., Suhadak, S., \& Handayani, S. R. (2017). The effects of capital structure and good corporate governance on dividend policy and firm value an empirical research at banks listed in Indonesia stock exchange for the period of 2008-2012. Journal Administrasi Bisnis, 9(2), 51-69.

Durand, D. (1952). Costs of debt and equity funds for business: trends and problems of measurement. In Conference on research in business finance (pp. 215-262).

Fama, E. F., \& Babiak, H. (1968). Dividend policy: An empirical analysis. Journal of the American Statistical Association, 63(324), 1132-1161.

Hijazi, S. T., Bin Tariq, D., et al. (2006). Determinants of capital structure: A case for Pakistani cement industry. Lahore Journal of Economics, 11(1), 63-80.

Miller, M. H., \& Modigliani, F. (1961). Dividend policy, growth, and the valuation of shares. the Journal of Business, 34(4), 411-433.

Monks, R., \& Minow, N. (2004). Corporate governance. Blackwell, Oxford.

Shah, A., \& Khan, S. (2007). Determinants of capital structure: Evidence from Pakistani panel data. International Review of Business Research Papers, 3(4), 265-282.

Shleifer, A., \& Vishny, R. W. (1997). A survey of corporate governance. The Journal of Finance, 52(2), 737-783.

Van Horne, J. C., \& Wachowicz, J. M. (2005). Fundamentals of financial management. Pearson Education.

Yasser, Q. R., Entebang, H. A., \& Mansor, S. A. (2011). Corporate governance and firm performance in pakistan: The case of karachi stock exchange (kse)-30. Journal of Economics and International Finance, 3(8), 482-491. 